\title{
POTENTIAL SCENARIOS OF CONCERN FOR HIGH SPEED RAIL OPERATIONS
}

\author{
Michael Carolan \\ Laura Sullivan \\ Volpe National Transportation Systems Center \\ US Department of Transportation \\ Cambridge, MA 02142
}

\begin{abstract}
Currently, multiple operating authorities are proposing the introduction of high-speed rail service in the United States. While high-speed rail service shares a number of basic principles with conventional-speed rail service, the operational requirements on a high-speed rail system are typically more demanding than those for conventional-speed operations. The operating environment will require specialized maintenance and inspection procedures, enhanced protection or gradeseparation of highway-rail crossings, effective separation of other rail traffic, and detection of potential hazards along the track to help ensure the safety of the system. With the required implementation of positive train control (PTC) by passengercarrying rail operators, the frequency and/or severity of several types of railroad accidents can be decreased. While all of these measures will contribute to the overall system safety, incidents that pose a threat to passenger and crew safety may still occur that cannot be prevented through the design of the operating environment alone. It is important to consider these types of incidents when selecting the rail vehicles for use in a particular operation, and include appropriate crashworthiness and occupant protection measures.
\end{abstract}

This paper presents a series of example scenarios of some of the potential hazards that may affect the safe operation of highspeed passenger trains in the United States. These situations are drawn from actual accidents that have occurred in the U.S. and abroad. The scenarios provide a starting point for discussing system safety features, which includes vehicle crashworthiness and occupant protection features.

As an operating environment may be designed to limit the likelihood of certain types of incidents from occurring, three different hypothetical high-speed operating environments are discussed in this paper. While the number of potential scenarios varies with each operating environment, in all environments it is important to consider the need for a train's crashworthiness features to mitigate the consequences of potential incidents.

\section{INTRODUCTION}

Overall railroad safety can generally be described as including two broad categories: accident prevention and accident mitigation. Both accident-prevention and accident-mitigation features may be included in the design of the right-of-way and the vehicles traveling upon it. A combination of prevention and mitigation measures determines the overall safety of a given system.

Accident prevention measures are included within a system to avoid the occurrence of incidents in the first place. Some examples of these measures include diligent employees, positive train control (PTC) systems, a rolling stock maintenance plan, a right-of-way (ROW) maintenance plan, and appropriate separation of other traffic. A combination of multiple accident prevention measures can help to prevent a wider range of accidents than a single accident prevention measure.

Accident mitigation measures are included within a system on the determination that not all accidents are preventable. While the inclusion of accident prevention measures within a system's design may decrease the likelihood of certain accident scenarios to a very low level, there are hazards that may present themselves later in the operation of a system that cannot be known to the designers of the system. Accident mitigation measures attempt to decrease the negative outcomes of the accidents that are not prevented, including minimizing the number and severity of injuries and the number of fatalities. Some examples of accident mitigation measures include 
occupied volume integrity (OVI), crash energy management (CEM), side and roof strength of the rail vehicle, occupant protection measures, and override prevention measures.

While the initial accident-prevention and accident-mitigation measures may be selected during the design of the system, it is important to maintain feedback during the actual operations to more accurately reflect the potential hazards facing the system. An effective system for tracking close-calls, recurring maintenance issues, and other potential safety hazards that do not become full-blown accidents can be a useful tool for determining the appropriateness of the initially-designed accident prevention and mitigation strategies. Additional prevention and/or mitigation strategies may be appropriate based upon the specific hazards revealed during system operations.

This paper presents a number of accident scenarios that are important to consider in the design of a high-speed railroad system. In particular, this paper is a study of accidents that would not be prevented by a PTC system or occurred despite the presence of a PTC system. Potential strategies to prevent or mitigate the scenarios in this paper are also included in the discussion of each scenario. These accidents were chosen as representative of the hazards modern railroad operations must face, but are not considered to include all of the potential hazards that a high-speed rail system may face. While not all of the example accidents discussed in this paper occurred on high-speed rail lines, the lessons that can be learned from each accident are relevant to high-speed rail operations.

\section{PTC-PREVENTABLE ACCIDENTS}

Positive train control is a system designed to prevent certain types of train accidents. According to the Federal Railroad Administration (FRA),

Positive Train Control (PTC) refers to technology that is capable of preventing train-to-train collisions, overspeed derailments, and casualties or injuries to roadway workers (e.g., maintenance-of-way workers, bridge workers, signal maintainers) operating within their limits of authority as a result of unauthorized incursion by a train. PTC is also capable of preventing train movements through a switch left in the wrong position. [1]

This accident prevention measure will decrease both the frequency (number) and severity (speed) of the types of accidents the system was designed to prevent. Accidents that would not have occurred had a PTC system been installed and properly functioning are referred to as PTC-preventable.

\section{NON-PTC PREVENTABLE ACCIDENTS}

Even with the inclusion of PTC on a railroad system, accidents outside of the limits of the PTC system may still occur. In some situations, the PTC system may be capable of mitigating the consequences, such as by slowing a train before it strikes an obstruction on the track ahead. For example, a broken rail may interrupt a track circuit and cause a PTC system to apply the brakes on a train approaching the broken rail. If the train is traveling sufficiently quickly, it may be slowed but not completely stopped before traveling over the broken rail. Since not all accidents can be prevented through techniques currently available, it is important to include accident mitigation measures in the system. A number of these mitigation measures have been included in the design of the rail vehicles themselves.

Historically in the United States, these mitigation measures have been prescribed design requirements for passenger railroad vehicles. Some of the design requirements that address accident mitigation are the static end strength of the occupied volume (49 CFR 238.203), collision (\$238.211) and corner post (§238.213) requirements, side (§238.217) and roof (§238.215) strength requirements, and requirements on the seats and interior fittings (\$238.233) of the vehicle. For operations above $125 \mathrm{MPH}$ in the U.S., Tier II requirements are applicable and include equivalent or more stringent requirements than those for lower-speed Tier I passenger equipment.

To facilitate study of accidents that have already occurred, it is important to understand the operating environment that the rail equipment is facing. To that end, three hypothetical operating environments have been developed for this paper. The three operating environments all feature high-speed rail operations. They have been developed to span a range of possible conditions, from a totally dedicated high-speed rail system to high-speed trains running on shared track with commuter and freight equipment. The environments are discussed from most restrictive to least restrictive in terms of the types of equipment permitted on the right-of-way. As the environment grows less restrictive, additional hazards present themselves that were previously addressed by the design of the operating environment. These additional hazards may be mitigated by the inclusion of appropriate measures included in the design of the rolling stock.

\section{OPERATING ENVIRONMENT 1}

Operating Environment 1 contains high-speed rail equipment traveling on a dedicated ROW. This environment does not include any other types of train traffic or grade crossings. The highest speed operations occur within Environment 1. This environment requires a highly-effective train control system whose capabilities meet or exceed the requirements for PTC 
described previously in this paper. This environment also requires a maintenance-of-way safety plan and strict standards for the maintenance of the rolling stock and the operating environment itself.

\section{Potential Hazards for Operating Environment 1}

Four general hazards are discussed in Operating Environment 1:

- Derailment (broken wheel, broken rail, natural disaster, etc.)

- Failure of train control system to keep trains apart

- Maintenance-of-way equipment not tracked by train control system

- Debris encountered on track

\section{Example of Derailment: Grayrigg, UK (2007)}

This accident occurred on February 23, 2007 near Grayrigg in Cumbria, England. A Virgin Pendolino train was travelling at approximately $95 \mathrm{mph}$ when it passed over a switch. The switch was not in a proper state of repair, and the switch rail was able to move as the train passed over. All of the cars making up the train derailed, with several moving down an embankment and coming to rest on their sidewall structures. A photograph of the accident equipment is shown in Figure 1 with annotations indicating each car's position in the consist. As a result of this accident, one passenger was fatally injured and twenty eight passengers and two crew members were seriously injured [2].

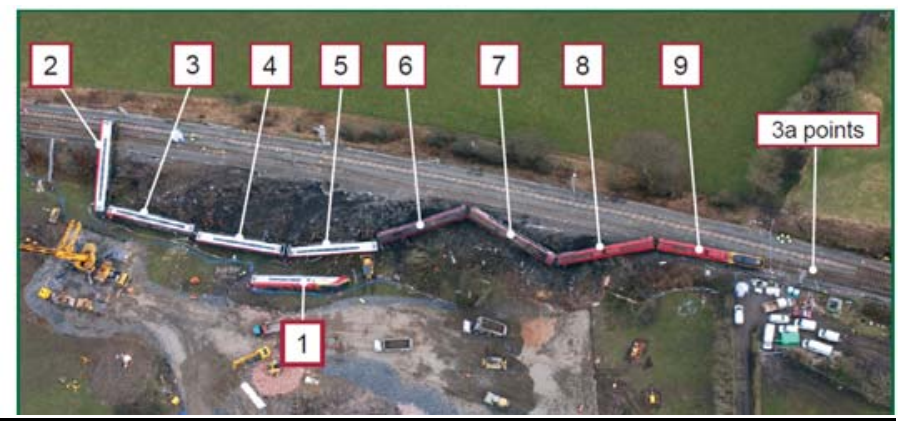

Figure 1. Grayrigg Derailment [2]

While some of the train cars involved in this derailment came to rest on their sides, the occupied volumes of the cars were substantially intact. The majority of the injuries in this accident were the result of secondary impacts, and not loss of occupied volume. The accident mitigation measures designed into the equipment, in particular the sidewall strength and interior configuration, were successful in mitigating the negative consequences of this particular collision. As a result of this accident, inspections of 1473 switches were conducted to determine if any other switches of the same design were in a similar state as the accident switch. This inspection effort did not find any switches in the same state of repair, but did find some components that had precursors to failure [2]. This increased scrutiny of the maintenance of track components is an example of accident prevention through maintenance-ofway.

\section{Example of Control Failure: Washington, DC, USA (2009)}

On June 22, 2009, a train-to-train collision occurred on the Washington, D.C., Metro system. This system is equipped with a train control system that is capable not only of stopping trains at the appropriate location, but of accelerating the trains to their allowable speed and maintaining that speed. In this accident, one train (Train 112) was following a second (Train 214). Train 214 received and complied with a stop signal. However, the wayside hardware that detects the presence of a train within a signal block experienced a malfunction and did not "see" the stopped train. As a result, Train 112 was given instructions to proceed as if the track ahead was unoccupied [3].

The operator of the second train saw the stopped train on the track ahead and initiated emergency braking. However, there was insufficient space between the two trains to stop the second train, and it struck the rear of the standing train. The lead car of the trailing train telescoped through much of its length, resulting in nine fatalities. Figure 2 is a photograph of the two trains in their post-accident positions.

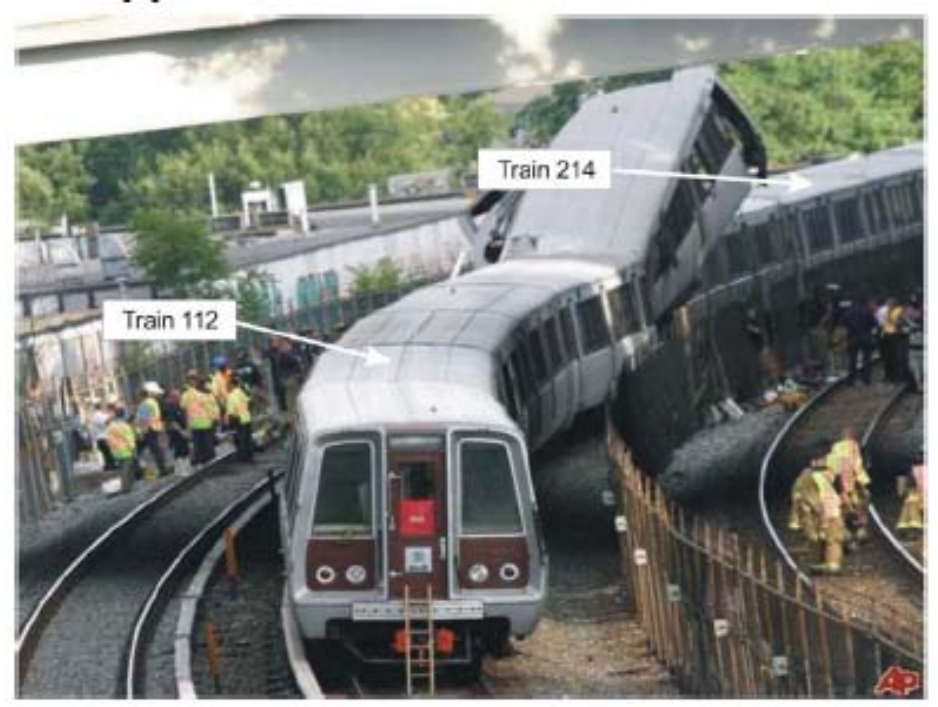

Figure 2. Post-accident Photograph of Washington, D.C. Metro Accident [3]

In this particular accident, the leading car of the trailing train experienced a significant loss of occupied volume. In its report 
on the accident, the National Transportation Safety Board (NTSB) stated:

With regard to the survivability of the accident, the investigation found that the structural design of the 1000-series railcars offers little occupant protection against a catastrophic loss of survival space in a collision and this contributed to the severity of the occupant injuries and fatalities [3].

While the operating environment was equipped with a sophisticated train-control system that was designed to prevent two trains from striking one another, the system failed in such a way as to allow an accident to happen. In its report, the NTSB stated that a similar signal system malfunction occurred in 2005, resulting in two near-misses between trains. In the 2005 incidents, collisions were prevented by employee intervention. The report also states that while enhanced testing procedures were developed to ensure the control system components were functioning properly these procedures were unfamiliar to the technicians that were to be implementing them.

In this accident, multiple shortcomings in system safety occurred which compromised the accident prevention and mitigation strategies. The train control system was able to fail in such a way that it did not prevent two trains from attempting to occupy the same block. While similar signal system failures had occurred, improved maintenance procedures were not being followed by all employees tasked with inspecting these components. The trains themselves were not equipped with accident mitigation features sufficient to prevent the gross loss of occupied volume in the lead car of the striking train.

\section{Example of MOW Equipment on Tracks: Lathen, Germany (2006)}

This accident occurred on a magnetic levitation (maglev) demonstration track in Lathen, Germany, on September 22, 2006. A maintenance-of-way vehicle was operating over the tracks to ensure the right-of-way was clear of debris. A maglev train carrying employees of the company operating the demonstration site struck the maintenance vehicle at approximately $120 \mathrm{mph}$ [4]. Twenty-three passengers were killed, and another ten received serious injuries. While this track did have a safety system that was capable of preventing this type of accident from occurring, the system was not turned on at the time of the accident [5]. Figure 3 is a photograph of the damaged lead car of the maglev train after the accident [6].

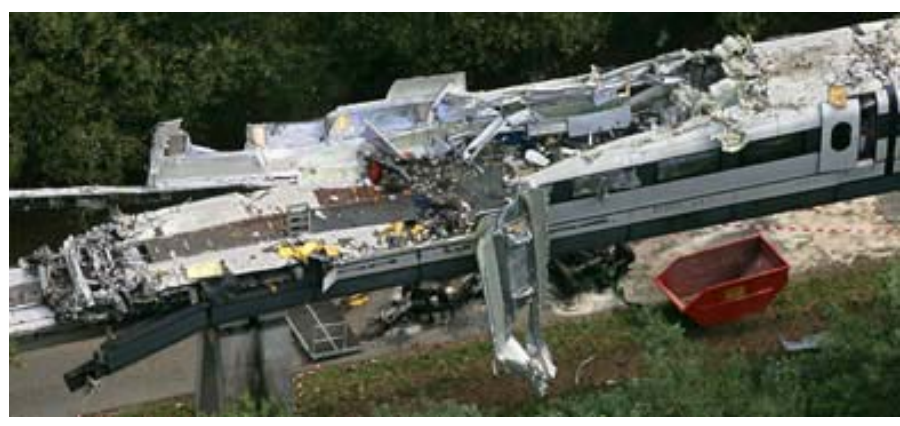

Figure 3. Post-accident Photograph of Lead Car, Transrapid Maglev Train [6]

It is unclear from the publicly-available information what crashworthiness features were included in the design of the maglev vehicles. Accident-prevention features designed into the system did include an automatic braking system that could prevent two trains from striking one another if they appeared to be in danger of striking one another. However, the control system allowed operations to occur without the safety system engaged.

\section{Example of Debris on Tracks: Selby, UK (2001)}

The fourth example of potential accidents occurring within Operating Environment 1 occurred in Selby, U.K., on February 28, 2001. In this particular accident, a motorist was driving an SUV with an automobile in tow. The SUV drifted from the highway, through a fence, across a field, and through a second fence before coming to rest across a set of train tracks that passed beneath the highway. The driver of the SUV contacted police to notify the railroad of his vehicles obstructing the track. Before the railroad could be contacted, a passenger train traveling at approximately $125 \mathrm{MPH}$ struck the road vehicles and derailed, fouling a second set of tracks in the right-of-way. This train then travelled further down the right-of-way, where it impacted an oncoming freight train on the adjacent track it was fouling [7]. As a result of this accident, ten people on board the passenger train were killed, including the engineer. While operations in Environment 1 do not include freight trains, a second passenger train could be involved in this type of incident with equally serious consequences. 


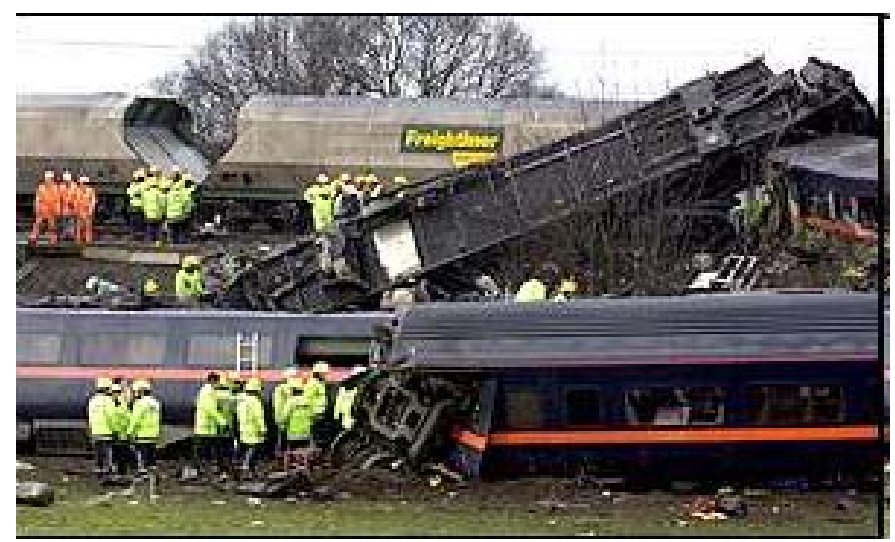

Figure 4. Post-collision Photograph of Passenger and Freight Trains, Selby, UK [8]

In this accident, there was not sufficient time for the SUV driver to contact the police, the police to contact the railroad, the railroad to contact the engineer of the train, and the engineer to bring the train to a stop before striking the highway vehicles on the track. While technology exists that may alert a train engineer of an obstruction fouling the right-of-way, there are practical limitations to the usefulness of such alerts. Even if a train engineer can be instantly notified of an obstruction ahead, the train will take time (and, consequentially, distance) to be brought to a stop. During their investigation of the Selby accident, the Health and Safety Commission (HSC) examined a wide range of railroad accidents involving highway vehicles. Their conclusion was that preventing highway vehicles from entering the railroad right-of-way, rather than preventing trains from hitting them, was the best approach toward reducing risk [7].

With the increased maximum operating speeds of high-speed trainsets there is an increased distance required to stop the train. For high-speed operations, it is especially important to design the system in such a way that large obstructions, such as cars and trucks, can be prevented from entering the right-ofway. Figure 5 contains a number of hypothetical speed versus distance braking curves as a means of estimating the distance required to stop a train from an initial speed of $200 \mathrm{MPH}$. Each line represents a different braking rate, ranging from 1.2 $\mathrm{MPH} / \mathrm{second}$ to $2.0 \mathrm{MPH} / \mathrm{second}$. As Figure 5 demonstrates, at the highest assumed braking rate of $2.0 \mathrm{MPH} /$ second a train travelling at $200 \mathrm{MPH}$ will require nearly 15,000 feet to come to a stop.

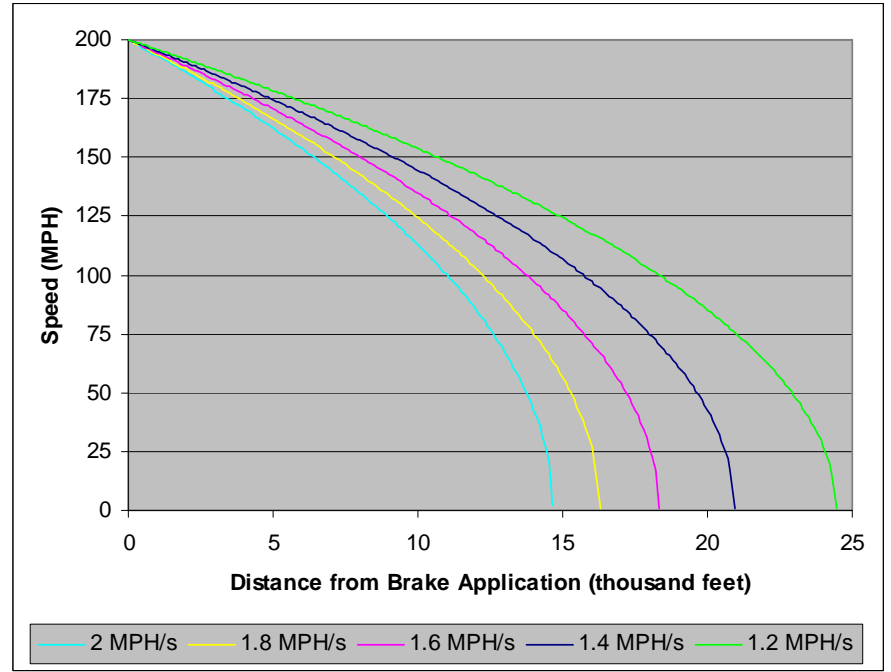

Figure 5. Example Braking Curves

While the primary justification for exclusion of train-to-train collisions from the scenarios of concern for high-speed operations in the United States is an effective train control system, train control systems may only serve to mitigate some collisions, not prevent them entirely. It is important to recognize the possibility of a collision, albeit at a decreased speed, on lines equipped with PTC systems. While striking the motor vehicle obstructing the tracks resulted in the train partially derailing at Selby, the consequences of striking the oncoming train were very severe. Accident mitigation strategies are still an appropriate component of overall system safety for reducing the negative consequences of such a collision.

\section{OPERATING ENVIRONMENT 2}

Operating Environment 2 contains high-speed rail vehicles operating on dedicated tracks within a shared right-of-way. This environment features high-speed operations, with speeds less than that of Environment 1. Tracks are not shared with any other types of vehicles; however freight or conventional-speed passenger trains may operate on adjacent tracks within the ROW. This environment may feature a limited number of grade-crossings, all of which feature enhanced safety measures. Similarly to Environment 1, Environment 2 features a highlyeffective train control system. Environment 2 also requires strict maintenance standards and a maintenance-of-way safety plan.

\section{Potential Hazards for Operating Environment 2}

The potential hazards affecting Environment 1 are also potential hazards for Environment 2. In addition, Environment 2 includes one additional hazard:

- Derailed conventional equipment fouling ROW 


\section{Example of Derailed Conventional Equipment: Littleton, CO (2007)}

This particular example demonstrates one of the potential hazards associated with different types of equipment operating over dedicated tracks in a shared (or separated, but adjacent) right-of-way. In metropolitan Denver, Colorado, light rail service is operated in close proximity to freight rail tracks. On December 11, 2007, a coal train experienced a derailment on a section of freight tracks adjacent to the light rail tracks, derailing approximately 20 cars and spilling coal into the light rail right of way [9]. At the time of the derailment, a light rail train was traveling on the track closest to the freight right-ofway. The light rail train could not stop in time and struck the coal that was obstructing its tracks. There were no fatalities when the light rail train derailed.

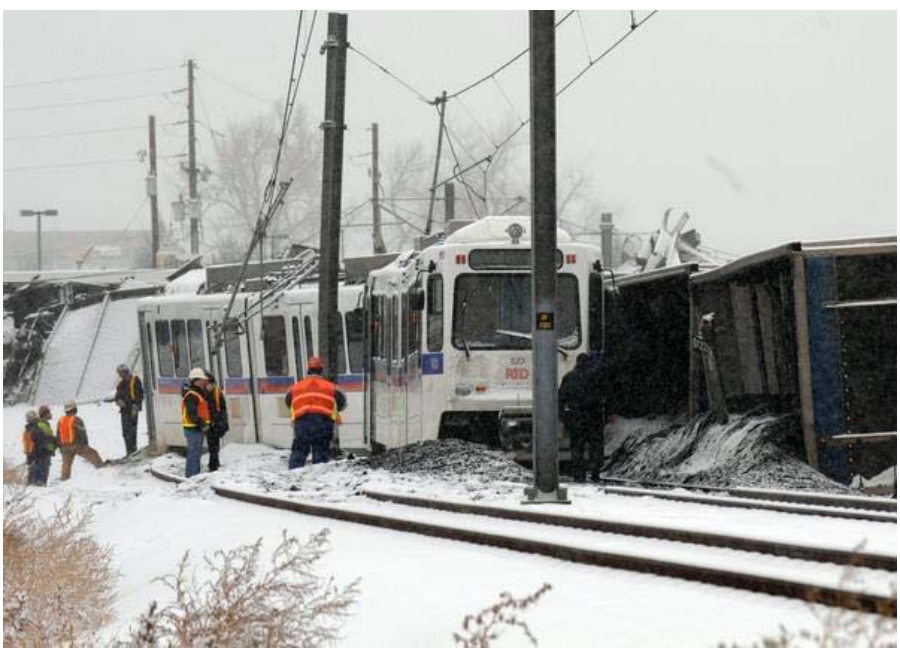

Figure 6 - Photograph Showing Light Rail Train and Derailed Coal Cars [10]

This accident emphasizes a potential hazard that results from the presence of dissimilar railroad equipment operating on adjacent rights-of-way. While placing dissimilar pieces of equipment on separate rights of way will prevent train-to-train collisions as a result of operating two trains over the same section of track, this case illustrates that more effective measures for separation of rights-of-way may be necessary to truly prevent the possibility of impacts between operating equipment and derailed equipment. Where the possibility of such a collision remains it is important to consider the design of the passenger vehicle and select appropriate crashworthiness features to mitigate any such collision.

Because of the short amount of time between the freight train's derailment and the passing of the light-rail train, it is not likely that equipping the light-rail line with intrusion-detection components would prevent this accident. Where the possibility of such a collision remains it is important to consider the design of the passenger vehicle and select appropriate crashworthiness features to mitigate any such collision.

\section{OPERATING ENVIRONMENT 3}

Operating Environment 3 contains high-speed rail vehicles operating over conventional-speed infrastructure. Operations in this environment are limited to conventional speeds, regardless of the type of equipment in use. The tracks may be shared with commuter, intercity, or freight operations. As such, the tracks may be subjected to increased loading and require appropriate maintenance. This environment may include highway-rail grade-crossings. Effective train control, appropriate maintenance of rolling stock, and a maintenanceof-way safety plan are all characteristics of Environment 3.

\section{Potential Hazards for Operating Environment 3}

The potential hazards affecting operations in Environment 1 and Environment 2 are also potential hazards for Environment 3. In addition, Environment 3 includes two additional hazards:

- Highway vehicle obstructing grade crossing impacted by high-speed train

- Collision with conventional equipment

\section{Example of Highway Vehicle Struck by High-speed Train: Bierne, France (1997)}

In France, high speed TGV trains travel on dedicated highspeed rights-of-way as well as conventional railroad tracks. When high-speed trains are being operated over conventionalspeed infrastructure the trains are restricted to operating at conventional speeds. One of the characteristics of the conventional operating environment is the presence of highway-rail grade crossings.

On September 25, 1997, a TGV trainset was operating over conventional lines when it struck an asphalt paving machine that had gotten stuck at a grade crossing near Bierne [11]. The speed of the train at impact was approximately $81 \mathrm{MPH}$. Figure 7 shows the leading power car after the accident, lying on its side. 


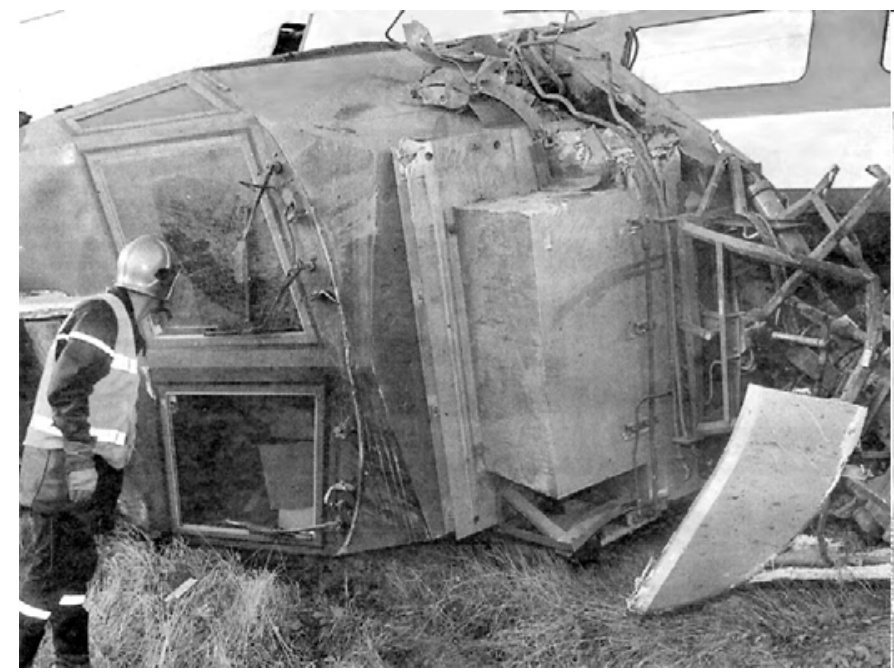

Figure 7. Leading TGV Power Car from Bierne, France Collision [11]

There were no fatalities in this accident. This can partially be attributed to the crashworthy design of the TGV consist that was involved in the collision. In 1988, a similar accident occurred at Voiron, France, with a TGV travelling at $68 \mathrm{MPH}$ striking a heavy truck at a grade crossing. Two fatalities occurred in this collision, which served as a catalyst for a research program into the crashworthiness of the future TGV equipment [12]. In both of these accidents heavy equipment became stranded on a grade crossing.

Several accident prevention strategies can be employed to increase the safety of grade crossings. Employing improved roadway designs that reduce the likelihood of vehicles becoming stuck at the grade-crossing and improved barriers to prevent drivers from entering a crossing shortly before a train decreases the likelihood of a vehicle being on the tracks when a train comes through. Restricting the speed at which a train may pass through a grade-crossing provides a greater likelihood of stopping if an obstruction is seen, and may reduce the consequences of striking an object that cannot be avoided. Removing the grade crossing further reduces the possibility of a highway vehicle being struck by a rail vehicle.

\section{Example of Collision with Conventional Equipment: Canton, MA (2008)}

The Northeast Corridor is a railroad line connecting Washington, D.C. with Boston, MA that serves the high-speed Acela Express trains, Amtrak Regional trains, commuter trains, and freight trains. At its narrowest, the Northeast Corridor is double-tracked.

On March 24, 2008, a freight car loaded with lumber was dropped at a private siding. The freight car became unsecured and rolled out of the yard without being derailed. The freight car rolled downhill, which brought it onto the Northeast Corridor.

At the same time, a commuter train was traveling on the Northeast Corridor in the direction from which the freight car originated. The commuter train engineer realized the signals indicated something occupying the track ahead and brought his train to a stop. The freight car struck the passenger train before it could be backed up. The damaged freight car and passenger locomotive following the collision are shown in Figure 8.

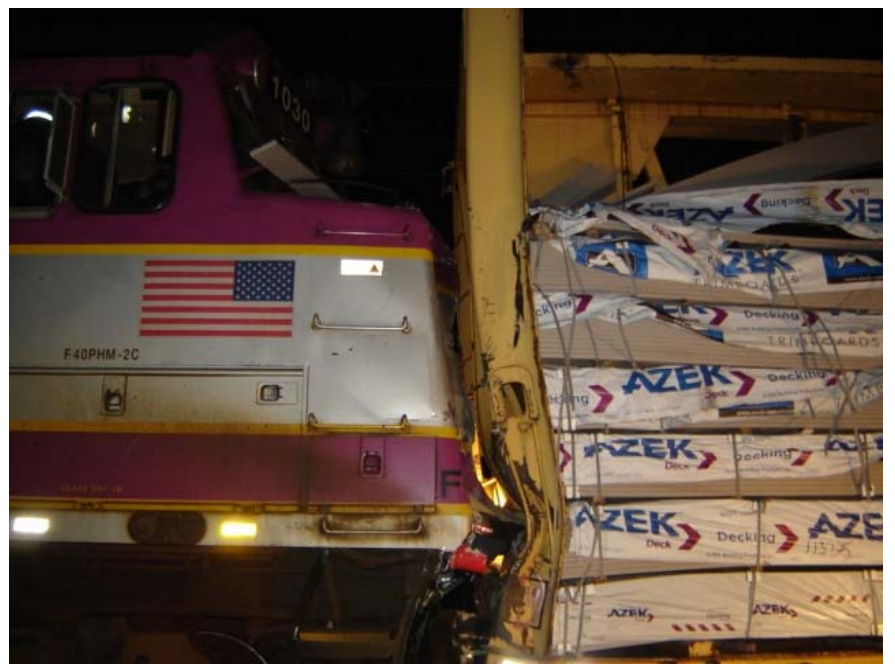

Figure 8. Post-accident Photo from Canton, MA (2008)

While the speed of the freight car is estimated at being between 25-40 MPH, the force of the impact was sufficient to drive the standing passenger train back by approximately 47 feet [13]. There were no fatalities in this accident, but there were 150 people with reported injuries.

This accident demonstrates the need for crashworthy vehicles even in an environment with a train control system. While there were precautions in place to prevent a freight car from leaving the siding, the precautions failed to keep this car on its siding. The signal system worked as intended, and alerted the commuter train engineer that something was on the track ahead. The commuter engineer acted properly and brought his train to a stop. However, at this point the locomotive engineer was unable to take any further action to prevent his train from being struck. In this accident, the locomotive and passenger cars were sufficiently crashworthy to protect the crew and passengers from fatal injury.

\section{SUMMARY}

Effective train control systems, including PTC systems, are capable of preventing certain categories of train accident. These accidents include overspeed derailments, train-to-train 
collisions, intrusion into work zones, and movements through improperly-lined switches. However, control systems are not capable of preventing every type of train accident. Even with a sophisticated control system and diligent train handling accidents can still occur that may pose a threat to the lives of the crew and passengers.

While a combination of accident prevention strategies will reduce the severity and frequency of certain types of accidents there are still accidents that may occur. In the event of an accident that is not fully prevented by system design the consequences to passengers and crew may be mitigated through inclusion of appropriate crashworthiness features on the highspeed rail vehicles. The total safety of the system is dependent on the combination of accident prevention measures and accident mitigation strategies employed in the operating environment.

\section{ACKNOWLEDGEMENTS}

This work was performed by the Volpe Center as part of the Equipment Safety Research Program sponsored by the Office of Research and Development of the Federal Railroad Administration. Mr. Kevin Kesler is Chief of the Equipment and Operating Practices Division. Mr. David Tyrell is the Crashworthiness Team Leader at the Volpe Center.

\section{REFERENCES}

1. "Positive Train Control.” Federal Railroad Administration. http://www.fra.dot.gov/Pages/1521.shtml Accessed 10/26/2010.

2. Report 20/2008. "Rail Accident Report: Derailment at Grayrigg, 23 February 2007.” Rail Accident Investigation Branch, Department for Transport. www.raib.gov.uk. Accessed 10/27/2010.

3. Railroad Accident Report NTSB/RAR-10/02. "Collision of Two Washington Metropolitan Area Transit Authority Metrorail Trains Near Fort Totten Station, Washington, D.C., June 22,2009.” National Transportation Safety Board. http://www.ntsb.gov/publictn/2010/RAR1002.pdf. Accessed 10/27/2010.

4. "Deadly Crash on German Monorail.” BBC News. Published 9/22/2006. http://news.bbc.co.uk/2/hi/europe/5370564.stm. Accessed 10/26/2010.

5. "Negligent Manslaughter: Two Managers Convicted of Transrapid Crash.” Spiegel Online. http://www.spiegel.de/international/germany/0,1518,555083 ,00.html. Accessed 11/9/2010.
6. "Engineers Convicted in Maglev Accident.” The Local Germany's News in English. http://www.thelocal.de/national/20080523-12045.html. Accessed 10/27/2010.

7. "The track obstruction by a road vehicle and subsequent train collisions at Great Heck 28 February 2001 - A report of the Health and Safety Executive investigation” Health and Safety Executive, 2002. http://www.railreg.gov.uk/upload/pdf/incident-greatheckfinal-optim.pdf. Accessed 10/27/2010.

8. "BBC NEWS| UK| In pictures: Selby rail tragedy." http://news.bbc.co.uk/2/hi/uk news/1193939.stm. Accessed 11/3/2010.

9. "Littleton light rail down for the count." Mitchell, K., Gonzales, M., and Leib, J. The Denver Post. Published $12 / 11 / 2007$. http://www.denverpost.com/huntfish/ci 7691056. Accessed 11/5/2010.

10. Sangosti, R.J. Denver Post Photograph. http://www.denverpost.com/portlet/article/html/imageDispla y.jsp?contentItemRelationshipId=1749952. Accessed $11 / 5 / 2010$.

11. "TGVweb - TGV Accidents" http://www.trainweb.org/tgvpages/wrecks.html. Accesed $11 / 2 / 2010$.

12. "Safety of High Speed Guided Ground Transportation Systems - Collision Avoidance and Accident Survivability - Volume 1: Collision Threat.” DOT/FRA/ORD-93/02.I. Final Report - March, 1993.

13. "Runaway Freight Car.” Boston Globe Graphic. http://www.boston.com/news/local/massachusetts/articles/ 2008/03/27/runaway freight_car/ Accessed 11/2/2010. 